Saudi Journal of Business and Management Studies Abbreviated Key Title: Saudi J Bus Manag Stud ISSN 2415-6663 (Print) |ISSN 2415-6671 (Online) Scholars Middle East Publishers, Dubai, United Arab Emirates Journal homepage: https://saudijournals.com

Review Article

\title{
Field Work in Qualitative Research Applicable To Economic- Administrative Sciences
}

Dr. José René Arroyo-Ávila, Dr. J. Emilio Méndez-González*, Dra. María del Rosario de Fátima Alvídrez-Díaz, Dr. Oscar Alejandro Viramontes-Olivas

Fulltime Teachers in Business Management, Strategic Management, Administrative Audit and Entrepreneurship Development in Accounting and Management Faculty- Autonomous University of Chihuahua UACh, México

DOI: $10.36348 /$ sjbms.2020.v05i12.006

| Received: 15.12.2020 | Accepted: 26.12.2020 | Published: 30.12.2020

*Corresponding author: J. Emilio Méndez-González

\section{Abstract}

In a knowledge generation process, not only the design of the instruments that allow obtaining the data to comply with the objectives of any investigation is important, but it is vital that these instruments are validated so that the final result of the interpretation of the results provide greater confidence in the conclusions, granting scientific validity to the study. Care must be taken in relation to ethical treatment in the field work of research, for which the existence of an Ethics Committee is of the utmost importance since, among other actions, it contributes to the protection of the rights of individuals and of the communities participating in the research project, ensuring the respect and care of people, living beings and the environment, which is part of the research. The nature of the research was qualitative, non-experimental, descriptive, transeccional design. The way in which the information was collected for the research was bibliographic. As a result it will be mentioned that it is necessary to consider that the field work requires trust, patience and security in the acceptance of the participants, capacity of adaptation and acceptance of the facts, versatility, to obtain the necessary data, persistence in the comparison of the data obtained and decision to overcome the confusion. It is vital that the instruments designed are properly validated to give scientific certainty to the results obtained.

Keywords: Instruments, validation, ethics, field work, field research.

Copyright (C) 2020 The Author(s): This is an open-access article distributed under the terms of the Creative Commons Attribution 4.0 International License (CC BY-NC 4.0) which permits unrestricted use, distribution, and reproduction in any medium for non-commercial use provided the original author and source are credited.

\section{INTRODUCTION}

Qualitative research is a process in which different visions intervene, which aims to study phenomena and determine the relationships that exist between their components Rueda [17]; refers to characters, attributes or non-quantifiable faculties that can describe, understand or explain social phenomena or actions (individual or group) of the human being Cerda [4], which addresses the reality of cultural processes, from a subjective perspective, with the that an attempt is made to understand and interpret human actions, their experiences, their experiences and their feelings, in order to create ways of being in the real world; Its purpose is to build knowledge about social reality, based on particular conditions and the perspective of those who originate it and live it González [9].
Qualitative research is used to explore the reality of social phenomena, based on the subjective experiences of the subjects who are immersed in a certain context Portilla Chávez, Rojas Zapata, \& Hernández Arteaga [16], it is inductive and is directed towards the discovery of social realities and not the verification Hernández, I., Alvarado, \& Luna [10].

Qualitative research is one that produces descriptive data derived from people's own words, whether spoken or written, and their observable behavior; The researcher sees the setting and the people from a holistic perspective (the people and the settings are considered as a whole), where all the perspectives are valuable, as well as all the settings and people are worthy of study Taylor \& Bogdan [19]. It seeks to extract, from observations made to an object of study, the valid conclusions for the proposed phenomenon 
and, through inductive reasoning, identify and circumscribe the reality under study to give it social identity, so that the reasoning of character Comparative constitutes the strategy for abstraction and theoretical generation Verd \& Lozares [22]. Inductive reasoning lays the knowledge base of social phenomena to later conceive and relate them to theory.

\section{Field work or Field research}

To begin with the obtaining of data in qualitative research, applicable to Economic Administrative Sciences, the consent and approval of the participating subjects and entities or communities is required, consequently it is necessary to have the appropriate mechanisms for its presentation, facilitating the Researchers' entry into the field of work or field research, which in this case will be related to an entity or organization of a business, social or governmental nature. Fieldwork requires investigative skills to capture the data required by the investigation, among which we can highlight: confidence in the context; patience and security in accepting participants; combination of flexibility and rigor in processes; adaptability and acceptance of facts; versatility, making use of the various ways to obtain the necessary data; persistence in comparing the data obtained; decision to overcome confusion at times when unexpected events occur; and, meticulousness to take care of the details, both in the selection of the techniques for the data collection, as well as the instruments.

In field work, the researcher must face three decisions:

1) Entering the field, which implies the consent or permission of the authorities of the institution or organization for the implementation of the techniques and the application of the instruments for obtaining data, which also allows permanent observation of the particular scenario and the context in general; The most difficult moment of the investigation is to set foot in the field of action for the first time and know what to do at that moment, then to know who is who in the group of participants, to physically recognize the place, to identify the formal and informal norms of the entity; In this dynamic, two questions arise that the researcher must answer, where am I? and who am I with? This experience suggests an initial approach to the field through pilot studies, as a preliminary step to the study.

The interaction that takes place between the researcher and the participants is very important, and the treatment of the different roles that the researcher acquires, according to their participation in the process, while the participants also acquire different roles, according to the degree of data key they provide. In qualitative research, the researcher is the main mediating instrument for data collection, this role is very useful if it is taken into account that to develop the objectives he can resort to his own experience, knowledge, imagination and susceptibility, in addition to the fact that the Success of data collection depends to a great extent on the relationship and integration that is achieved with the participants, with the communities under study, according to the purposes of the data collection; Generating environments of trust requires permanent effort on the part of the researcher, an environment that must be motivated so that it lasts throughout the entire field work and the entire investigative process. Not having an environment of trust, definitely limiting and can send the ongoing investigation to failure.

2) The productive obtaining of data, which inevitably leads to continue making decisions that require changes and adjustments in the research project. In addition, fieldwork activities require flexibility in the times provided for in the work schedules; It is essential that there is clarity between researchers and participants about what is wanted, then the door is opened to information that allows the productive obtaining of data that is of interest to the development of the research; the criteria of sufficiency and adequacy must be taken into account, which avoid unnecessary data. Sufficiency refers to the amount of data rather than the number of subjects; data saturation occurs when the new information does not contribute anything significant to the study; The adequacy has to do with the selection of the data according to the theoretical needs of the study and the emerging model, at this stage of the fieldwork the data obtained and organized can be contrasted with the same participants.

3) The exit from the field work, which occurs at the moment in which the researcher has integrated into the context and the participants until they become part of it; It is the moment in which it is no longer possible to obtain more productive data, since it loses sensitivity to daily activities; the participants and the members of the work team lose perspective of the context, because it is considered native to that reality; It is then evident that the unequivocal signal to leave the job has arrived, even if it feels that not all the data has been obtained, that there is an interview that was not done, that a document was missing that could have been reviewed or that there was one more issue left tackle, even though he has spent a lot of time in the field. 
This, rather than helping, is disadvantageous, because the data begins to be repetitive and important apprehensions are not achieved; Leaving the field can be a difficult time for the researcher, it means breaking the attachments that have been built up over time. It is recommended at this stage to depart, reducing the frequency of visits and informing the community or participants that this stage of the research is ending Gil Flores, García Jiménez, \& Rodríguez Gómez [7]; McCracken [12]; Morse [14].

\section{The Instruments Validity}

The instrument is a means or resource that makes it possible to approach the research participants to collect the necessary data from primary sources; is a methodological resource that is part of the technique, which is designed for the researcher to get closer to the research participants and collect the data that allow him to develop the objectives and answer the research questions. Each instrument chosen by the researcher establishes the approach mechanism that is had with the participants and determines the specification of the data that the investigation requires, generally in the form of questions or aspects to be observed, which correspond to the previously defined categories of analysis Bernardo Carrasco \& Caldero Hernández [2]

Instruments are the main tool used in field work, which is the way to obtain data from the reality under study. The nature of the research determines the techniques and instruments to be authorized at different moments of the investigative process, their selection, design and application being of high importance, since the success or failure of the investigation depends on them Munarriz [15].

Within a research process, for a data collection instrument to be considered adequate, rigor and quality are required in the validation process of the instrument itself, since they are important qualities in the subsequent interpretation of the results and provide greater confidence to the conclusions of the research, which finally gives scientific validity to the study.

To support data collection instruments, two fundamental principles must be taken into account:

- The reliability of an instrument, which is the degree to which it produces consistent and coherent results with the question, with the objectives, with the categories and with the methodological design of the research; an instrument is reliable when its results are consistent and stable.

- Validity, which determines whether an instrument, a procedure, a sampling and a methodological design are appropriate to obtain correct or adequate results and conclusions, validity aims to maintain that the propositions with which the research concluded are legitimate, hence its importance; If the designs, the sample and the instruments are not valid, the whole investigation is incorrect and therefore the conclusions are derived from inadequate premises.

Reliability is a necessary but not sufficient condition for the validity of an instrument, which will have a high level of validity to the extent that the research results reflect a complete, clear and representative image of the reality or social phenomenon that is study.

If the instruments are reliable and valid, the investigation will have high reliability of success and scientific validity.

There are factors that affect the principles of reliability and validity of data collection instruments:

- Improvisation, where instruments are designed lightly, that is, without adequate research planning; with instruments decontextualized of the problem, that is, decontextualized from the initial frame of reference, from the objectives, from the categories of analysis or from the research methodology; and instruments that are distant from the characteristics of the sample, that is, they are not consistent with the profiles of the participants.

- The imposition, which among the actions that damage its validity and reliability, is imposing instruments implemented in contexts different from the object of study (especially, instruments elaborated in other countries with cultures very different from ours), without a prior analysis that determines its validity and adaptability to the new situation; and, finally, make adaptations to instruments without considering that the very essence of the original instrument may be lost.

In the validation process, it is pertinent to test the instruments, to evaluate or estimate their effectiveness in data collection in field work. In qualitative research there are two types of validation:

- The pilot test, in which not only the instrument is tested, but the entire research planning stage, that is, the problem, the justification, the reference framework, the objectives, the categories and the methodological design; Its purpose is to evaluate technical aspects and improve or correct all the deficiencies found before making the application in the field work; The test will function as a first step to obtain pertinent data in the object investigation, that is, detailed information on the type, order, clarity and design, both of the questions and of the aspects to be observed. 
The piloting is carried out by applying the instruments to a reduced number of participants in the sample, recommending their application to $10 \%$ of the total sample, preserving its characteristics; With the data obtained, the entire process of organization, structuring, systematization and triangulation is carried out, in order to verify difficulties and successes of the instruments; the difficulties or problems that arise must be adjusted in relation to the categories of analysis Iraossi [11]; Escobar-Perez \& Cuervo-Martínez [6]; Burgos Navarrete \& Escalona [3].

- Expert judgment, which is a generalized practice to validate data collection instruments in qualitative research, is defined as an informed opinion of research experts with a productive track record in the subject; recognized experts in the scientific community who can provide information, evidence, judgments and assessments. The selection of experts is a critical part of this process, which is why some criteria are established: they must have experience in making judgments and making decisions based on evidence, experience and level of academic training; must demonstrate authority and reputation in the academic-scientific community; must be willing and motivated to participate as an expert and make evaluative judgments about the instruments; and, must show impartiality, self-confidence and adaptability Uktin [20]; Skjong \& Wentworth 18].

To carry out the expert judgment process of a data collection instrument, one must:

- Define the intended objective, in this section the researchers must be clear about the purpose of the trial;

- Take into account academic training, experience and recognition in the scientific community when selecting experts; a minimum of three is proposed, two of whom must be experts in measurement and evaluation.

- Be explicit in the dimensions and in the categories of indicators that address each of the items of the instruments, this will allow the expert to evaluate their relevance, sufficiency and pertinence.

- Specify the objective of the instrument, having to provide the expert with information related to the use of the instrument, to contextualize it with respect to the test, increasing in turn the level of specificity of the evaluation, since the validity of the items is directly related to its use.

- Establish the differential weights of the dimensions of the instrument, this is only done when some of the dimensions have different weights.

- Design the judgment sheet, which is prepared in accordance with the evaluation objectives and with their respective indicators for rating.

- Validate the agreement between the judges, in the case of qualitative research the evaluation criteria are taken into account.

- Prepare the conclusions of the judgment, which will be used to make the instrument adjustments McGarland, Berg, Tebb, Lee, \& Rauch [13]; Archer [1].

\section{The ethical aspects of research}

In the process of obtaining data that occurs in any type of research, it is very important to always take into consideration the following fundamental methodological and ethical principles: knowledge is a constructive production, its interpretive character is generated in the need to give meaning to the expression of the subject studied; the knowledge production process in the Economic-Administrative Sciences is interactive and is conceived in the dynamic action between the researcher and the subject or subjects investigated, giving an essential dimension to the process of knowledge production; the significance of singularity has a legitimate level in the production of knowledge, in qualitative research it is not legitimized by the number of subjects studied, but by the quality of what is expressed; From the ethical point of view, it is necessary to assume the person with their dignity, understanding, character and culture, as the axis of research action, that is the point that adds particular complexity to qualitative research.

A prominent element in the ethical aspects of research is the Ethics Committee, whose purpose is to: ensure that the ethical aspects of research are reflected in the rules and investigative practices; his work is from the educational and the dialogic; It is framed in the protection and defense of human beings and other living beings that are part of the investigation processes, but also in the recognition and protection of intellectual property rights, as minimum values in the current context.

This type of body must be regulated by regulations that indicate obligations and executions that it must carry out and promote in the investigative community the strict observance of the legal, communication, respectful and broad dialogue on the issues it addresses. Its procedures should be oriented fundamentally towards:

- Contribute to the protection of the rights of individuals and communities participating in the research project.

- Ensure respect and care for living beings and the environment, which is part of the investigation.

- Promote education and training in ethics in research.

- Study the research projects carried out in the academic community from an ethical point of 
view.

- Follow up and monitor the research projects to which the endorsement is granted, especially those that have greater risks due to their biopsycho-social, economic, political and environmental implications.

- Inform interested teachers about endorsed projects.

- Generate an information system guaranteeing its confidentiality.

- Implement self-assessment and continuous improvement processes.

- Collaborate with research centers in promoting good research practices González [8]; Emmanuel [5].

\section{CONCLUSIONS}

In all research it is indisputable that data collection must be carried out, depending on the focus of the research problem, being one of the fundamental stages that favors the creation and development of scientific knowledge about the object reality; selecting it properly is one of the great responsibilities of the researcher. The data collection process is so important that the research may be meaningless without the data obtained through the appropriate techniques and instruments that were applied in the field work, data that lead to giving an answer to the problem or the question posed.

The rigor of the investigation depends largely on the selection of techniques and the design of instruments, since the data collection process is entrusted to them. Techniques and instruments are relevant requirements to approach field work, which is why the researcher must consciously reflect on their role in the selection or design of the instrument (as the case may be) to give way to the field work that respond to the expectations and needs of the investigation.

An important and relevant point, within the research process, is the validation of the instruments, since it gives certainty to the interpretation of the results and gives greater confidence to the conclusions of the research, which finally gives scientific validity to the study

Finally, without being less important, it is relevant to mention that research, as a result of the productive effort, must take care of the protection and defense of human beings and other living beings that are part of the research processes, in addition to giving recognition and protection of intellectual property rights as minimum values in the current context.

\section{REFERENCES}

1. Archer, M. S. (1995). Realistic social theory. Morphogenetic approach. Santiago de Chile: Alberto Hurtado University Editions.
2. Bernardo Carrasco, J., \& Caldero Hernández, J. (2000). Learning to research in Education. Madrid, Spain: Rialp Editions

3. Burgos Navarrete, F., \& Escalona, E. (2017). Pilot Test: Validation of instruments and procedures to collect Anthropometric Data for Ergonomic purposes. Engineering and Society UC, 12(1), 3147.

4. Cerda, H. (2011). The elements of research, how to recognize them, design and build them. Bogotá: Editorial Magisterio.

5. Emmanuel, E. (1999). What makes clinical research ethical? Seven ethical requirements. In A. Pellegrin, \& R. Macklin, Research in Human Subjects: International Experience (pp. 33-46). Santiago de Chile: PAHO / WHO Regional Bioethics Program.

6. Escobar-Pérez, J., \& Cuervo-Martínez, A. (2008). Content validity and expert judgment: An approach to its use. Advances in Measurement. (6):27-36.

7. Gil Flores, J., García Jiménez, E., \& Rodríguez Gómez, G. (1996). Qualitative Research Methodology. Cadiz, Spain: Editorial Aljibe.

8. González, A. (2000). Moral and Ethics. Origin of a conceptual difference and its significance in contemporary ethical debate. Philosophical Yearbook. (33):797-832.

9. González, E. (2013). About the state of the art or about a recent past in qualitative research with a hermeneutical approach. Unipluriversidad, 13(1):60-63.

10. Hernández, I., Alvarado, J., \& Luna, M. (2011). Qualitative research methodology. Syllogism more than concepts, 8(1), 27-38.

11. Iraossi, G. (2006). The Power of Design: A User's Guide to Administering Surveys, Interpreting Results, and Influencing Respondents. Washington D.C., United States: World Bank.

12. McCracken, G. (1988). The long interview. Qualitative research methods. Volume 13. Ontario, Canada: Sage Publications.

13. McGarland, D., Berg, M., Tebb, S. S., Lee, E. S., \& Rauch, S. (2003). Objectification of content validity: conducting a content validity study in social work research. Social Work Research, 27(2), 94-104.

14. Morse, J. (1994). Critical questions in qualitative research. Ontario, Canada: Sage Editions.

15. Munarriz, B. (s.f.). Qualitative Research Techniques and Methods. Obtained from the University of the Basque Country: http://ruc.udc.es/dspace/bitstream/handle/2183/853 3/CC-02art8ocr.pdf? sequence $=1$

16. Portilla Cháves, M., Rojas Zapata, A., \& Hernández Arteaga, I. (2014). Qualitative research: A reflection from education as a social fact. University Magazine. Teaching, Research, Innovation, 3(2):86-100. 
17. Rueda, J. (2007). Ethnographic and / or qualitative research and teaching at the university. Mexican Journal of Educational Research, 12 (34), 1021-1041.

18. Skjong, R., \& Wentworth, B. (2000). Expert judgment and perception of risk. Retrieved from ResearchGate:

https://www.researchgate.net/publication/2650323 03_Expert_Judgment_and_Risk_Perception

19. Taylor, S. and Bogdan, R. (1984). Introduction to qualitative research methods. The search for meanings. New York: John Wiley and Sons.

20. Uktin, L. (2006). A method of processing unreliable expert judgments about parameters of probability distributions. European Journal of Operations Research, 175 (1), 385-398.

21. Valles, M. (1994). Qualitative Techniques of Social Research. Methodological reflection and professional practice. Obtained from UPV. Pedro de Valdivia University: http://academico.upv.cl/doctos/ENFE4072/\%7B0156537F-94C8-43CF-B91A6ABB5550C70F\%7D/2013/S2/IT_Valles_Tecnica s_cualitativas.pdf

22. Verd, J., \& Lozares, C. (2016). Introduction to Qualitative Research. Madrid, Spain: Editorial Síntesis. 